\title{
1 Decision support framework for space-use efficiency and arrangement of public services
}

4 AUTHOR 1 (Corresponding author)

5 Robert Rusek, Ph.D

6 University of Girona, Institute of Applied Informatics

7 Av. LluisSantaló S/N, Bloc P IV

8 Research group eXiT

917003 Girona, Spain

10 Tel: +34622370928

11 robert.rusek@udg.edu

12

13 AUTHOR 2

14 Joan Colomer Llinas, Ph.D

15 University of Girona, Institute of Applied Informatics

16

17 AUTHOR 3

18 Joaquim Melendez Frigola, Ph.D

19 University of Girona, Institute of Applied Informatics

20 Abstract

21 This article focuses on the issue of a sustainable space-use in public facilities and

22 beneficial arrangement of services. Uncorrelated facility planning and service

23 programming as well as environmental factors cause discrepancies between space

24 demand and space supply leading to space overuse or underuse. To enhance the

25 functional and economic efficiency of public facilities a conceptual framework,

26 which is a planning and evaluation tool for decision support, is presented and

27 discussed on examples. The framework consists of two decisive elements: space- 
28 use analysis and service compatibility analysis. The first one aims to determine the

29 degree of space utilization in multiple public buildings while the latter reports on

30 how services are related to each other in terms of their compatibility. The article

31 explains these concepts in details on examples.

\section{Keywords}

34 Public facilities, public services, space efficiency, space-use analysis, multi-service 35 facility

\section{Funding}

38 This work has been funded through the following projects: CROWDSAVING (Ref.

39 TIN2016-79726-C22-R) as well as Secretaria d'Universitats i Recerca del Departament

40 d'Economia i Coneixement de la Generalitat de Catalunya [2017-SGR-1551 and 2014

41 FI_B00971].

\section{Introduction}

43 In our time cities became a driving force of European development (Rotmans, van Asselt

44 \& Vellinga 2000). They compete with each other for private finance and investments

45 (Kourtit, Nijkamp, \& Partridge, 2013). For this reason, numerous initiatives aim to 
46 measure, benchmark and compare them, such as: European Smart Cities (Vienna

47 University of Technology, 2007), City Benchmarking Data (Citybenchmarkingdata.com, 48 2017) or Best Places (Bestplaces.net, 2019), to name a few. The competition takes place

49 especially in the field of public services due to their direct impact on citizens' quality of

50 life (Lee \& Lee, 2014). In this context, a service is understood as an intangible process or

51 activity provided by the public authority on behalf of citizens and offered in a facility - a

52 built, indoor environment. Thus, the quality of public services depends, in great part, on

53 facilities - buildings where those services are offered. This indoor environment should

54 support performance of public services (Kwok \& Warren, unpublished report, 2005) and

55 its structure must assure appropriate spatial conditions for all service activities (Wiggins,

56 2010). However, public services are constantly affected by a number of external factors,

57 such as social, economic, political and environmental which impacts the services

58 changing number of activities for which space expansion or reduction is necessary.

59 Facilities, as built environment, are not very prone to such changes. In consequence,

60 there are many examples of facilities and services that do not fit each other spatially

61 causing inefficiencies and citizen's dissatisfaction (Marsal-Llacuna, 2010).

62 Taking into account a changing environment, the number of public facilities and

63 the variety of services offered on the scale of a city, it is a big challenge for the public

64 sector in terms of how to manage this set of services and buildings (Zhang \& Gao, 2010).

65 In consequence there is little awareness about the space resources available in numerous 
66 public facilities. The service-space adjustment is usually carried out at the level of specific

67 buildings, however there is a lack of general awareness on space resources at the scale of 68 the entire city.

69 The issue of space-use is not new and has been in interest of researchers and 70 organizations for decades. A significant improvement in this field have been brought by 71 Pennanen (2004) who studied relation of work space and user activity. Moreover, Kim 72 and Fischer (2014) automatized the process of space-use analysis using ontology with 73 specific focus on educational buildings. Both contributions are focused on a detailed 74 analysis of building areas of specific facilities. However, to the authors' best knowledge 75 there is a lack of studies focused on a set of buildings of different types and characteristics $76-$ a typical amalgamation in a city context.

A lack of appropriate management results in overused and underused buildings.

78 Both of these situations should be avoided. Overused facilities impact negatively on 79 working conditions and decreases service quality, thereby preventing its development. 80 On the other hand, underused facilities waste space, which is an expensive asset. It is not 81 only because space is costly to buy and maintain, but also because space entails the 82 consumption of other valuable resources such as energy or water (Ibrahim, Yusoff, \& 83 Bilal, 2012). Kim, Cha \& Kim (2016) illustrated this matter on the example of a higher 84 education facility in the United Kingdom which uses annually $318 \mathrm{kWh}$ per square meter 85 on average. Therefore, the proper use of space is a determining factor with regard to 
86 prosperous facilities, and ensuring an adequate amount of space is crucial for service

87 quality on the one hand, and for economic efficiency on the other.

88 To this end, the framework for space-use efficiency and arrangement of public

89 services has been proposed. The purpose of this framework is to enhance space-use

90 (functional and economic efficiency) in public buildings. It is intended as a decision-

91 support tool for city governments since management of public facilities is usually

92 fragmented, limited to specific buildings or subsets of buildings. Therefore, a holistic

93 overview on all city facilities may provide a significant difference to support a

94 knowledge-based decision making. For this reason, the framework aims to: first, provide

95 situational awareness on space-use on multiple public buildings of different types;

96 second, identify underutilized buildings; and third: recommend how to combine

97 compatible services with the existing ones, converting traditional single service facilities

98 into multi service facilities and by this mean increase utilization rate and improve

99 efficiency.

100 Multi service or multipurpose facility (MSF) combines different services under

101 one roof and permits more than one activity to take place at the same time and location

102 (Batty, Besussi, Maat \& Harts, 2004). It also reduces the amount of urban land necessary

103 for provision of public services (Marsal-Llacuna, Leung \& Ren, 2011). According to

104 Suzuki and Hodgson (2003) MSF can improve the level of service and cost-efficiency

105 because combination of various services supports the economies of scale effect. For this 
106 reason, MSFs are widely practiced in public sector especially in high density areas (Batty,

107 Besussi, Maat \& Harts, 2004), where land prices are very costly (Suzuki \& Hodgson,

108 2003). In these parts, there are many examples of numerous services being allocated in

109 one facility. The substantial difference, however, is that those facilities have been usually

110 designed as MSF from conception. Reversely, the framework proposed in this paper aims

111 to create MSFs by taking advantage of existing buildings and retrofitting them with

112 additional and compatible services.

\section{Theoretical background}

114 This paper contributes to the state of the art by filling the gap between three well studied

115 issues: facility location problem on the one side and facility layout as well as scheduling

116 problem on the other.

117 The purpose of facility location problem is to find optimal place for facility 118 construction assuring good accessibility and minimizing costs. This topic has been widely

119 studied especially in the field of operations research (Shmoys, Swamy \& Levi, 2004), for

120 example by Teitz (1968), ReVelle (1987), or Athanasiou \& Photis (unpublished report, 121 2004).

122 On the other hand, facility layout problem seeks for the best arrangement of spaces 123 and activities within the building (Drira, Pierreval \& Hajri-Gabouj, 2007). It is used in 124 the design phase for allocation of space in new buildings or to repurpose space in the 
125 existing ones (Liggett, 2000). There are numerous studies dealing with this issue, for 126 example by Kusiak \& Heragu (1987), Meller, Narayanan \& Vance (1998), or Saraswat,

127 Venkatadri \& Castillo (2015). Furthermore, the scheduling problem is a decision-making

128 issue that is applied in manufacturing and service industries to deal with allocation of

129 resources and tasks over given periods of time (Pinedo, 2015). This topic has been studied

130 also in the facility management context, for example by Gupta \& Gupta (1988), Thabet

131 \& Beliveau (1994), or Zhao et al. (2014).

132 The proposed framework fills the gap between these three subjects. It does not 133 consider the process of building and locating new facility but instead it focuses on

134 facilities that have been built and used already for some time. Furthermore, it analyses a 135 set of buildings indicating those where utilization is far from optimal and proposes 136 compatible services to be combined with the existing ones instead of focusing on 137 particular buildings in details (which is a domain of facility layout as well as scheduling 138 problem). Consequently, it does not interfere into internal building structure or the task 139 organization, however the outcome of the framework may provide an indication for 140 internal layout or scheduling redesign.

141 The basic assumption of the framework is a logical separation of service (the 142 intangible component) from facility (the physical component). Habitually, facility and 143 service are considered as one entity (e.g. a school). However, it is necessary to break this 144 association and think of service and facility as of two independent items that should 
145 coexist together, e.g. school - building, and school - service of education, as depicted in

146 figure 1. The independent approach for facilities and services allows for a more flexible

147 and efficient space-use based on combination of different services in one facility creating

148 MSF. Combination of compatible services is vital because as Lee and Lee (2014) claim,

149 in most cases, the way that services are arranged reflects the internal structure of public

150 administration without considering functional relations between services which have a

151 significant influence on productivity and service quality. For this reason, compatibility

152 analysis should precede decision making on service arrangements whenever various

153 services are planned to be offered together.

154 Appropriate arrangement of services resulting in a more efficient space-use 155 require previous situation (or situational) awareness (SA). SA allows obtaining a clear 156 image of the current state of affairs that is indispensable for accurate decision making 157 (Gheisari \& Irizarry, 2011). It has a potential for facility management because it provides 158 mental picture of the situation and helps in making more accurate decisions based on 159 information that lead to improved performance; otherwise less than optimal decisions are 160 made (Gheisari \& Irizarry, 2011). SA in the context of decision making has been depicted 161 in Figure 2.

\section{Decision support framework}

163 Efficient management of public facilities and services requires a holistic approach 164 encompassing legal, managerial, social and technological instruments. Local 
165 governments have not enough power to deal with all these issues and therefore ad-hoc

166 solutions are applied to mitigate negative effects of this unfavourable situation. This, in

167 practice, translates into optimization that usually considers only economic aspect and is 168 narrowed to cost reduction (Pym, Taylor \& Tofts, 2007). For this reason, the presented

169 framework is an evaluation and planning tool allowing analysing two types of 170 relationships: service-facility and service-service, on numerous public facilities. It 171 consists of two decisive processes that correspond to each type of relationship. Space-use 172 analysis reflects the service-facility relationship and allows for determining current space 173 utilization - a crucial information for enhancing space economic efficiency on the one 174 hand, and assuring appropriate amount of space for all activities, on the other. Service 175 compatibility analysis reflects the service-service relationship and reports on how 176 services offered in one facility (or planned to be offered in one facility) are related to each 177 other in various aspects - a crucial information for service beneficial arrangements.

178 As depicted in Figure 3, the framework consists of four processes (data insertion, 179 space-use analysis, service compatibility analysis and decision making), one decision 180 point (verifying the number of services) and data repository (space-use inventory). At 181 the process' initial phase, data about facility area and quantitative description of service 182 or services is necessary. This information may be inserted manually or imported 183 automatically if such a repository is available. Next, the number of services is verified. If 184 more than one service is offered within the facility, compatibility analysis is performed 
185 and posteriorly, space-use analysis is executed. These processes are performed 186 automatically to provide information about how services are related to each other and 187 what their spatial needs are. The results are stored in a space-use inventory and the process 188 repeats for all considered facilities. Finally, the outputs set up a basis for the aware 189 decision making and are delivered to the decision maker. The key elements of the

190 framework: space-use analysis, compatibility analysis, space-use inventory and decision 191 making are described in details in the following sections:

\section{Space-use analysis}

193 Space-use analysis aims to determine service space needs and contrast them with facility

194 primary area where the service can be offered. It is important to stress that space-use has

195 to be considered not only from the economic point of view, but also the environmental 196 impact has to be taken into account. According to van den Dobbelsteen and de Wilde 197 (2004) space-use is strongly correlated with: use of building materials, energy and water 198 consumption, travel, ecology, health and safety. For this reason, determining factual

199 space needs is essential for economic as well as environmental reasons. The process of 200 space-use analysis has been depicted in Figure 4.

201 At the beginning of the space-use analysis process, facility and service are 202 evaluated independently. Facility has to be decomposed and the net internal area (NIA) 203 space available for service provision - is taken into account (space supply). 
204 Simultaneously, the service is decomposed to its activities. Each activity is characterized

205 by its type, duration and number of users. Based on this data, spatial requirements are

206 determined (space demand). Subsequently the two values are compared. If space demand

207 corresponds with space supply, the facility is performing well in terms of space efficiency

208 (space conformity). Otherwise there are some discrepancies that may take two forms:

209 space scarcity or space excess. The first one occurs when space demand surpasses the

210 space supply. This of course is not a desired situation because lack of space affects

211 conditions of service provision preventing it from performing its full potential. Space

212 scarcity is relatively easy to detect because usually service directors complain about it.

213 The other form of discrepancy occurs when facility offers more space than is required by

214 service or services hosted within. In such case facility satisfies the service spatial

215 requirements fully but is not economically efficient since space excess can be considered

216 as waste of resources. It is not so easy to detect since people's needs are unlimited and

217 service directors usually are not willing to report on having too many resources unless

218 they are rewarded for it. Thus, the determination of space needs has to be done in a more

219 objective way using specific standards, such as Occupant Load Factor (OLF) or even

220 Space Syntax in case of more complex facilities.

221 Subsequently, regardless the case (space conformity, space scarcity, space

222 excess), facility utilization rate is determined and results are presented for decision

223 making. The space-use analysis process has been exemplified on the research facility 
224 building of the Polytechnic School of the University of Girona. Activities that take place 225 in the facility were determined (research, professors' activity, IT infrastructure 226 maintenance and administration) and assigned to the corresponding spaces (research lab, 227 professors' office, IT workshop and administration office). Space demand has been 228 calculated by multiplying the number of users (participants) of every activity by 229 appropriate Area Per Person Factor (APPF). The value of this Factor was taken from the 230 Space Planning Guidelines (Facilities Services, 2009) and assigned to each activity. 231 Posteriorly, space demand and space supply have been calculated and their values 232 compared. This is presented in Table 1. The results of this exercise show space scarcity 233 for professors' activities $\left(-81.3 \mathrm{~m}^{2}\right)$, space equilibrium in case of IT infrastructure 234 maintenance $\left(0.05 \mathrm{~m}^{2}\right)$ and space excess in case of administration $\left(37.9 \mathrm{~m}^{2}\right)$ as well as 235 research $\left(572.4 \mathrm{~m}^{2}\right)$ activities. Considering the abovementioned values, the research 236 facility building has a significant overall space excess $\left(529 \mathrm{~m}^{2}\right)$. The most intuitive 237 conclusion from this study is that the building requires internal layout redesign to satisfy 238 spatial requirements of the professors' activities and moreover has plenty additional space

239 that could be utilized for other purposes. The final result can be also expressed in terms

240 of utilization rate as a proportion of space demand and space supply giving the result of $24173 \%$. 


\section{Service compatibility analysis}

243 Service compatibility analysis is a quantitative method of service comparison. Services

244 are compared in various aspects that characterize them in a comprehensive way from

245 different perspectives. Rusek et al. (2016) propose the following set of seven features

246 which describe a service from both: user as well as administration perspective:

247 Features describing a service from the user perspective:

248 - User - describes the proportional age structure of service users: Children, Youth, 249 Adults, Elderly.

250 - Nature - reflects a character of service from the user perspective: Administration,

251 Culture, Education, Health care, Safety, Social, Sports, Transport

252 - Presence - refers to the mode in which a service is delivered: In person (for services

253 which require in person presence of the citizen in a facility) and Virtual (for services $254 \quad$ which can be delivered online)

255

- Scope - refers to service accessibility. Service can be classified as Local (when it is

256 design to serve to local community, e.g. district library), or Global (when it is

257 dedicated to all city inhabitants, e.g. hospital or administrative services)

258 Features describing a service from the administration perspective:

- Affiliation - represents an administration department responsible for service

260 provision. This characteristic depends strictly on the context of a particular city due

261 to different organizational schemes. 
- Stakeholder - refers to all people who are involved in the service; not only its final 263 users, but also service staff and other, indirect participants. Alike the User 264 characteristic, Stakeholder reflects the age structure: Children, Youth, Adults and 265 Elderly.

266 - Delivery - refers to the mode of service, which can be a Front office (e.g. social 267 service with citizen attention), or Back office (e.g. administration).

268 Each of these characteristics has to be expressed quantitatively by assigning a 269 compositional value to each attribute. This value represents the degree to which the 270 attribute defines the service. For instance, if children are $80 \%$ of service users and adults $27120 \%$, the compositional values of these attributes would be 0.8 and 0.2 respectively.

272 Posteriorly, the distance between corresponding values of two services is calculated to 273 determine the degree of their coincidence.

274 For that purpose, we take advantage of the City-block distance which represents 275 a distance between two points as a sum of the absolute differences of their coordinates 276 (Panigrahi, 2014). The general City-block distance formula has to be normalized to 277 represent the final result as a percentage value instead of a number between 0 and 1 , and 278 it takes the following form:

$$
d(S 1, S 2)=100 \%-\left(\frac{1}{2} \sum_{i=1}^{n}|S 1 i-S 2 i|\right)
$$

280 To obtain the percentage value that reflects the degree of similarity, let us consider for 
281 example a user characteristic of two hypothetical services: Service 1 and Service 2. To 282 obtain the degree of their similarity, the values form Table 2 has been substituted into the 283 normalized City-block distance formula, as follows:

$d(S 1, S 2)=100 \%-\left(\frac{1}{2}(|32 \%-25 \%|+|50 \%-25 \%|+|10 \%-25 \%|+|8 \%-25 \%|)\right.$

$$
=100 \%-\frac{1}{2}(7+25+15+17)=100 \%-\frac{1}{2} 64=68 \%
$$
Thus, similarity of the user feature of Service 1 and Service 2 is equal to $68 \%$.

287 Values of other characteristics are to be calculated in the same way. The results obtained for all characteristics provide an overview of the total degree of similarity between Service 1 and Service 2. The overview of the process of service compatibility analysis is presented in Figure 5. The result of service compatibility analysis is a percentage value representing to 292 what degree the services are 'of their kind'. The higher the coincidence, the higher 293 probability of advantageous combination. To exemplify this, a thirty municipal services were selected from the city of Girona, Spain based on their diversity, to demonstrate services of different types and characteristics. To this end, the sample include: cultural,

296 education, administration, social, sport and heath care services. The finale result of 297 compatibility analysis is depicted in Figure 6 in compatibility matrix. Compatibility matrix indicates what services are compatible and could be offered together (values close to 100) and services which combination should be avoided (values 
300 close to 0 ). The compatibility value provides a common denominator for comparison of

301 different combinations of services. It does not establish fixed ranges of compatibility but

302 settle which combination of services is more adequate. For instance, if compatibility

303 degree of Service $\mathrm{x}$ and Service $\mathrm{y}$ is $67 \%$, and compatibility of Service $\mathrm{x}$ and Service $\mathrm{z}$ is

$30476 \%$, it means that combination of services $\mathrm{x}$ and $\mathrm{z}$ is more recommended because the

305 degree of their compatibility is higher. However, it would be improper to say that service

$306 \mathrm{x}$ is compatible with service $\mathrm{z}$ but incompatible with service $\mathrm{y}$. Thus, the matrix visualizes

307 compatibility of various services helping in taking decision on service (re)arrangements

308 to favour advantageous combinations and discriminate the unfavourable ones.

309 Space-use inventory

310 Space-use inventory is the outcome of the space-use analysis process and compatibility

311 analysis process. It contains information about space utilization in multiple public

312 facilities and characteristics of services offered within. This information is presented in a

313 visual and user-friendly form using Google Maps API as depicted in Figure 7, where

314 location of five evaluated facilities has been represented spatially by markers. Facilities

315 have been clustered into four quarters and highlighted with a corresponding colour: Q1 -

316 high utilization (over 75\%), dark-green colour; Q2 - mid-high utilization (between 50\%

317 and 75\%), light-green colour; Q3 - mid-low utilization (between 25\% and 50\%), orange

318 colour; Q4 - low utilization (less than 25\%), red colour. In addition, each marker holds a 
319 number representing the degree of facility utilization and encapsulates a more detailed

320 information about facility name, utilization and area, as it is shown on the example of

321 Cultural Centre Marfa (B).

322 In addition, the inventory contains information about type of service or services

323 that are offered in each facility together with their quantitative characteristic. This

324 characteristic is used for the purpose of service compatibility analysis in two ways. First

325 of all, in case of MSF, it is used for evaluation of services already combined and offered

326 together. The evaluation aims to determine whether this combination is favourable or not.

327 Furthermore, service compatibility analysis is also conducted to verify whether additional

328 service that is planning to be introduced fits the one that is being offered already.

329 Regardless the case, relationships between services are represented graphically to

330 facilitate interpretation. Figure 8 depicts compatibility analysis conducted to evaluate two

331 municipal services from Girona offered in the same facility: Service of City Historical

332 Archive and Service of Image Research and Dissemination. The distance between each

333 characteristic of two services has been calculated and represented graphically. All

334 characteristics aim to compare services from different perspectives. However, the type

335 and number of characteristics is flexible and can be adjusted if necessary. On the

336 presented example, services are fully compatible in three aspects: scope - reflecting that

337 both services are dedicated to all city inhabitants and not only the neighbourhood;

338 affiliation - telling that services are managed by the same administrative department; and 
339 delivery, indicating back office/front office balance. In addition, evaluated services

340 turned out to be almost fully compatible in the nature aspect which reflect how service is

341 categorized by its users (e.g. social, educational, cultural, etc.). Moreover, users of both

342 services are very alike considering their age (85\%). Similarly, services are very analogous

343 considering their stakeholders - all people that are interested or involved in service

344 provision (80\%). Finally, the presence characteristic uncovers the lowest (although still

345 high $-75 \%$ ) compatibility indicating whether user in person presence is required to

346 deliver the service or it can be accomplished virtually. Hence, the closer the value to

$347100 \%$, the more compatible the services are; and the closer the value to $0 \%$, the less

348 compatible the services are. High compatibility value is an indication of beneficial service

349 combination, while low compatibility value indicates services which combination should

350 be avoided. The collection of all types of relationships between services represented on

351 the radar chart is more convenient for decision making since it does not only provide a

352 total compatibility value, but also helps to understand why.

\section{Decision making}

354 The framework helps in obtaining SA on spatial resources and indicates possible service

355 combinations; however, it does not make decisions by itself. The final decision has to be

356 taken by decision maker - a human being. This responsible professional shall analyse the

357 results and combine them with his experience, human judgment and other intangible

358 factors such as policies and urban planning acts to take the appropriate decision. 
360 facility economic efficiency by maximizing space-use. Another one is to improve service

361 quality by enhancing space accordingly to the needs. The last objective is to increase

362 general performance by reorganizing services in the meaningful way.

\section{Maximizing space-use}

364 Maximizing space-use may be the objective of decision-making in case of facilities with

365 low space utilization rate. The space surplus can be leased to the private sector creating 366 new source of income. It may also be allocated for numerous purposes depending on 367 current needs: it can be utilized for introducing additional and compatible services 368 improving the offer of services and increasing the value added; it could be leased to the 369 non-governmental organizations for the development of their activities or given for social 370 purposes of the local community to make the environment more vibrant.

\section{Surface enhancement for service improvement}

372 Surface enhancement may be necessary if space scarcity has been detected during the space-use analysis. Surface enhancement aims to assure appropriate spatial conditions for services that require more space to develop their activities. In such cases finding larger

375 facility for the service should be considered. This however could be difficult and may

376 render additional cost or new facility construction. The compromise may be achieved by 377 moving a part of service (a subservice or activity) to another location in the way that 
378 makes the inconvenience minimal. This decision however has to be considered

379 individually for every case.

$380 \quad$ Service rearrangement

381 Service rearrangement may be required if the degree of service compatibility is relatively

382 low. Services offered together in one facility that are not related to each other waste the

383 potential that can be rendered when well-matched, compatible services are combined. A

384 fortunate combination of services creates collaborations, safes resources and citizen's

385 time thanks to shared uses. For this reason, service compatibility analysis should be

386 considered during the decision making process whenever various services or activities

387 are carried out simultaneously under one roof.

\section{Conclusions and future research}

389 Changing environment causes discrepancies between space needed for provision of

390 public services and the amount of space available in public facilities leading to space

391 overuse or underuse. This situation may affect service quality if the space is overused, or

392 cause waste of resources in case of underused spaces. In order to mitigate the effects of

393 this unfavourable situation, the framework for space-use efficiency and arrangement of

394 public services aims for enhancement of functional and economic efficiency in public

395 buildings. 
The framework is a decision-support tool providing situational awareness on

397 space-use on multiple public buildings of different types. It identifies underutilized

398 buildings and recommends how combine compatible services, converting traditional

399 single service facilities into multi service facilities.

$400 \quad$ The framework`s underlying assumption is a logical separation of service form

401 facility where it is offered. Service and facility are evaluated separately, but the results

402 are contrasted posteriorly. It consists of four key components: space-use analysis, service-

403 compatibility analysis, space-use inventory and decision making. Each of these elements

404 has been explained in details end exemplified:

405 - Space-use analysis evaluated service space demand and contrasted it with space

406 supply to disclose either space scarcity, conformity or excess.

407 - Service-compatibility analysis describes services quantitatively in different

408 aspects and calculates the distance between them to indicate how close they are

409 to each other.

410 - Space-use inventory contains results of space-use analysis and compatibility 411 analysis performed on various facilities.

412 - Decision making is supported by the results of the space-use inventory (situational 413 awareness) and may has one of the three objectives depending on the situation: 414 maximize space-use, space enhancement to improve the service conditions, or 415 service rearrangement. 
416 This paper contributes to the state of the art by:

417 1. Joint approach for optimization of public services and facilities, which used to 418 be considered either separately, or in the fixed relation (type of service 419 determines the type of facility, e.g. school), preventing a more efficient use of space.

2. Encouraging beneficial organization of public services not by proposing new problem on the other. The focus of this paper was stressed on the space-use aspect and compatibility of 432 public services. However, the possibilities of public facilities and services performance 433 improvement are much broader. Therefore, the authors postulate that the framework 434 application shall go in parallel with other e-government initiatives, in particular the 
435 process of public services virtualization. There are many services that do not require

436 citizen's presence and may be entirely accomplished online.

437 Much research also remains to determine the citizens' sentiments related to the 438 interaction with public services. Application of opinion mining tools would allow a better

439 understanding of citizen's needs and therefore provide the opportunity to take them into

440 consideration in future adjustments. In addition, discovering the patterns of the interaction

441 of the citizenry with the public services using of crowd sensing techniques would provide

442 the opportunity to anticipate the citizen's behaviour and organize space and services in

443 the user-friendly way.

\section{Acknowledgments}

445 This work has been funded through the following projects: CROWDSAVING

446 (Ref. TIN2016-79726-C22-R) as well as Secretaria d'Universitats i Recerca del

447 Departament d'Economia i Coneixement de la Generalitat de Catalunya [2017-SGR-1551

448 and 2014 FI_B00971].

\section{References}

450 Athanasiou, F., Photis, Y. (2004). "Combinatorial locational analysis of public services 451 in metropolitan areas. Case study in the city of Volos, Greece." 44th Congress of 452 the European Regional Science Association: Regions and Fiscal Federalism 453 Batty, M., Besussi, E., Maat, K., Harts, J. (2004). "Representing Multifunctional Cities: 454 Density and Diversity in Space and Time." Built Environment, 30(4), 324-337. 
455 Bestplaces.net. (2019). "Best Places to Live | Compare cost of living, crime, cities, schools and more. Sperling's Best Places." <http://www.bestplaces.net> (Mar. 2, 2019).

458 Citybenchmarkingdata.com. (2017). "City Benchmarking Data - Any data any city." $459<\mathrm{https}$ //citybenchmarkingdata.com> (Mar. 2, 2019).

460 Dobbelsteen van den, A., de Wilde, S. (2004). "Space use optimisation and sustainability — environmental assessment of space use concepts." Journal of environmental management, 73(2), 81-89.

Drira, A., Pierreval, H., Hajri-Gabouj, S. (2007). "Facility layout problems: A survey." Annual Reviews in Control, 31(2), 255-267.

465 Endsley, M. R., Garland, D. J. (2000). Situation awareness analysis and measurement, 466 Lawrence Erlbaum Associates, Publishers, Mahwah, NJ.

467 Facilities Services (2009). Space Planning Guidelines. Idaho State University.

468 Gheisari, M., Irizarry, J. (2011). “Investigating facility managers' decision making process through a situation awareness approach." International Journal of Facility Management, 2(1).

Gupta, J., Gupta, S. (1988). "Single facility scheduling with nonlinear processing times." Computers \& Industrial Engineering, 14(4), 387-393.

Ibrahim, I., Yusoff, W., Bilal, K. (2012). “Space Management: A Study on Space Usage Level in Higher Education Institutions.” Procedia - Social And Behavioral Sciences, 47, 1880-1887.

Kim, T., Cha, S., Kim, Y. (2016). "Space choice, rejection and satisfaction in university campus." Indoor and Built Environment., 27(2), 233-243.

Kim, T. W., Fischer, M. (2014). "Automated generation of user activity-space pairs in space-use analysis." Journal of Construction Engineering and Management, 140(5), 04014007. 
481 Kourtit, K., Nijkamp, P., Partridge, M. (2013). "The new urban world - opportunity meets challenge.” Regional Science Policy \& Practice, 5(2), 149-151.

483 Kusiak, A., Heragu, S. (1987). "The facility layout problem.” European Journal of 484 Operational Research, 29(3), 229-251.

485 Kwok, A., Warren, C. (2005). "Optimization of performance in facilities management." $486 \quad$ Pacific Rim Real Estate Society Conference, Melbourne.

487 Lee, J., Lee, H. (2014). "Developing and validating a citizen-centric typology for smart 488 city services." Government Information Quarterly, 31, 93-105.

489 Liggett, R. (2000). “Automated facilities layout: past, present and future.” Automation $490 \quad$ In Construction, 9(2), 197-215.

491 Marsal-Llacuna, M. L. (2010) La cosa publica i l'urbanisme, o, Per que tenim els 492 equipaments que tenim. Lleida, Pages Editors.

493 Marsal-Llacuna, M. L., Leung, Y. T., Ren, G. J. (2011). “Smarter urban planning:

494 match land use with citizen needs and financial constraints." Proc. International

495 Conference on Computational Science and Its Applications. Springer Berlin 496 Heidelberg, 93-108.

497 Meller, R., Narayanan, V., Vance, P. (1998). “Optimal facility layout design.” 498 Operations Research Letters, 23(3-5), 117-127.

499 Panigrahi, N. (2014). Computing in geographic information systems. CRC Press.

500 Pennanen, A. (2004). User activity based workspace definition as an instrument for 501 workplace management in multi-user organizations. Haahtela-kehitys Oy.

502 Pinedo, M. (2015) Scheduling: Theory, algorithms and systems. Springer International $503 \quad$ Publishing

504 Pym, D., Taylor, R., Tofts, C. (2007). "Public services innovation through technology." 505 Proc. International Conference on Management of Engineering \& Technology, 
Portland 27362739.

507 ReVelle, C. (1987). Urban public facility location. Handbook of regional and urban economics, 2, 1053-1096.

Rotmans, J., van Asselt, M., Vellinga, P. (2000). “An integrated planning tool for sustainable cities.” Environmental Impact Assessment Review, 20(3), 265-276.

Rusek, R., Marsal-Llacuna, M., Torrent Fontbona, F., Colomer Llinas, J. (2016). “Compatibility of municipal services based on service similarity." Cities, 59, 4047.

Saraswat, A., Venkatadri, U., Castillo, I. (2015). “A framework for multi-objective facility layout design.” Computers \& Industrial Engineering, 90, 167-176.

Sharp, T. (1996). "Energy benchmarking in commercial office buildings." Proc., of the American Council for an Energy-Efficient Economy, 321-29)

Shmoys, D. B., Swamy, C., Levi, R. (2004). "Facility location with service installation costs." Proc., fifteenth annual ACM-SIAM symposium on Discrete algorithms, Society for Industrial and Applied Mathematics, 1088-1097.

Suzuki, T., Hodgson, M. J. (2003). „Multi-service facility location models.” Annals of Operations Research, 123(1-4), 223-240.

Teitz, M. (1968). "Toward a theory of urban public facility location.” Papers of The Regional Science Association, 21(1), 35-51.

Thabet, W., Beliveau, Y. (1994). "Modeling Work Space to Schedule Repetitive Floors in Multistory Buildings.” Journal of Construction Engineering And Management, 120(1), 96-116.

530 Wiggins, J. (2010). Facilities manager's desk reference, Chichester, West Sussex, UK: Blackwell. 
532 Zhang X., Gao H. (2010). "Optimal Performance-Based Building Facility

533 Management." Computer-Aided Civil and Infrastructure Engineering. 25(4), 269534284 .

535 Zhao, J., Lasternas, B., Lam, K., Yun, R., Loftness, V. (2014). “Occupant behavior and 536 schedule modeling for building energy simulation through office appliance power 537 consumption data mining.” Energy and Buildings, 82, 341-355.

\section{$538 \quad$ List of tables}

539

540 Table 1. Comparison of space supply and space demand on the example of research facility.

\begin{tabular}{rlrcccr}
\hline Types of Spaces & $\begin{array}{l}\text { Space } \\
\text { supply }\end{array}$ & Activity & $\begin{array}{c}\text { Number of } \\
\text { users }\end{array}$ & $\begin{array}{c}\text { APPF } \\
\left(\mathrm{m}^{2}\right)\end{array}$ & $\begin{array}{l}\text { Space } \\
\text { demand } \\
\left(\mathrm{m}^{2}\right)\end{array}$ & $\begin{array}{r}\text { Supply- } \\
\text { demand } \\
\left(\mathrm{m}^{2}\right)\end{array}$ \\
\hline Research lab & 930.8 & Research & 64 & 5.6 & 358.4 & 572.4 \\
Professors' office & 855.3 & Professors' activity & 84 & 11.2 & 936.6 & -81.3 \\
IT workshop & 44.65 & IT infr. maintenance & 4 & 11.2 & 44.6 & 0.05 \\
Admin. office & 149.45 & Administration & 12 & 9.3 & 111.6 & 37.9 \\
\hline TOTAL: & 1980.2 & & & & 1451.2 & 529 \\
\hline Utilization rate: & & & & & $73 \%$ \\
\hline
\end{tabular}

541 Table 2. Values of attributes of User characteristic for Service 1 and Service 2.

\begin{tabular}{|r|c|c|c|c|}
\hline FEATURE: & \multicolumn{4}{|c|}{ User } \\
\hline ATTRIBUTES: & Children & Youth & Adults & Elderly \\
\hline Service 1 & $32 \%$ & $50 \%$ & $10 \%$ & $8 \%$ \\
\hline Service 2 & $25 \%$ & $25 \%$ & $25 \%$ & $25 \%$ \\
\hline
\end{tabular}



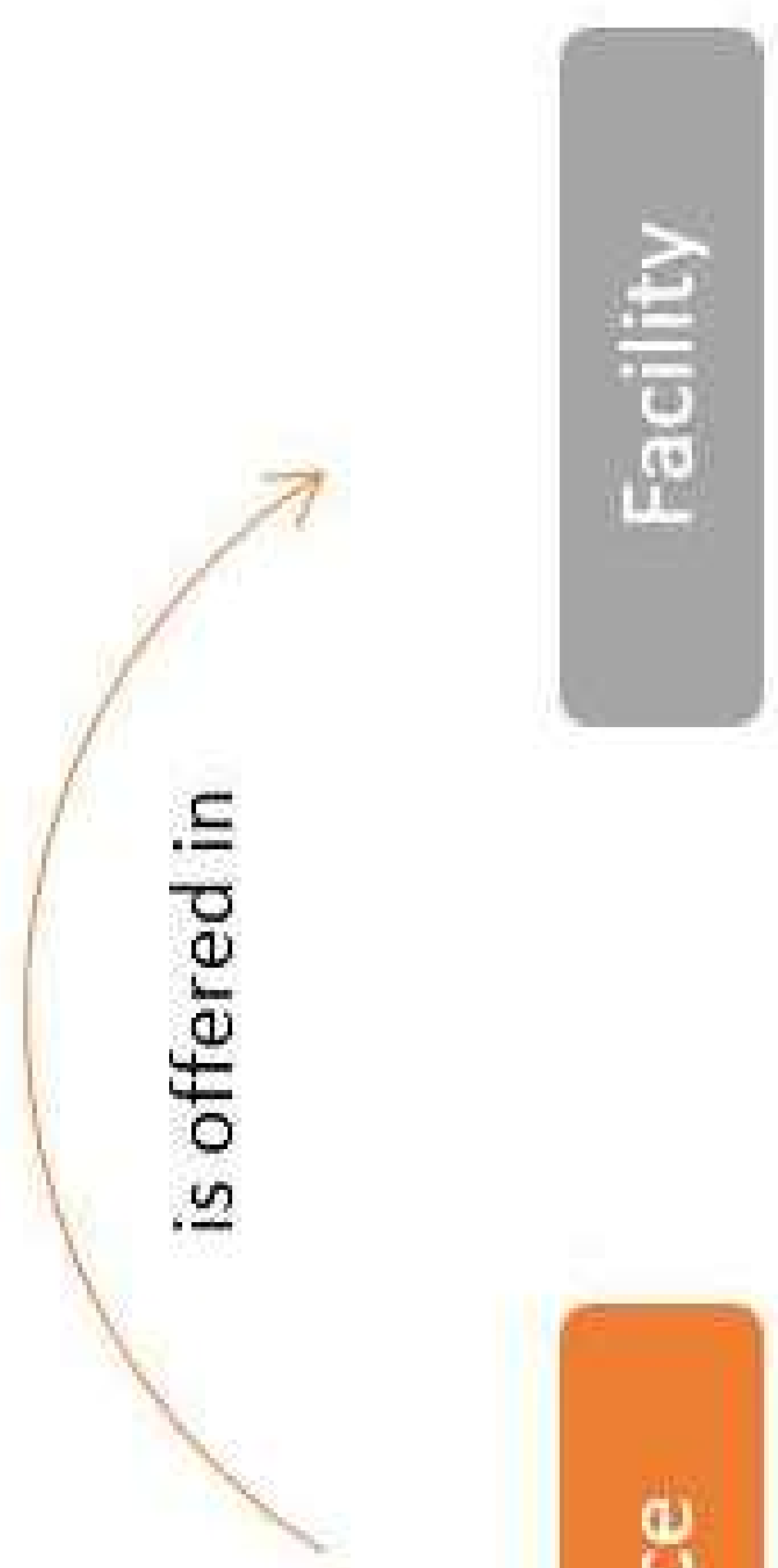

T5
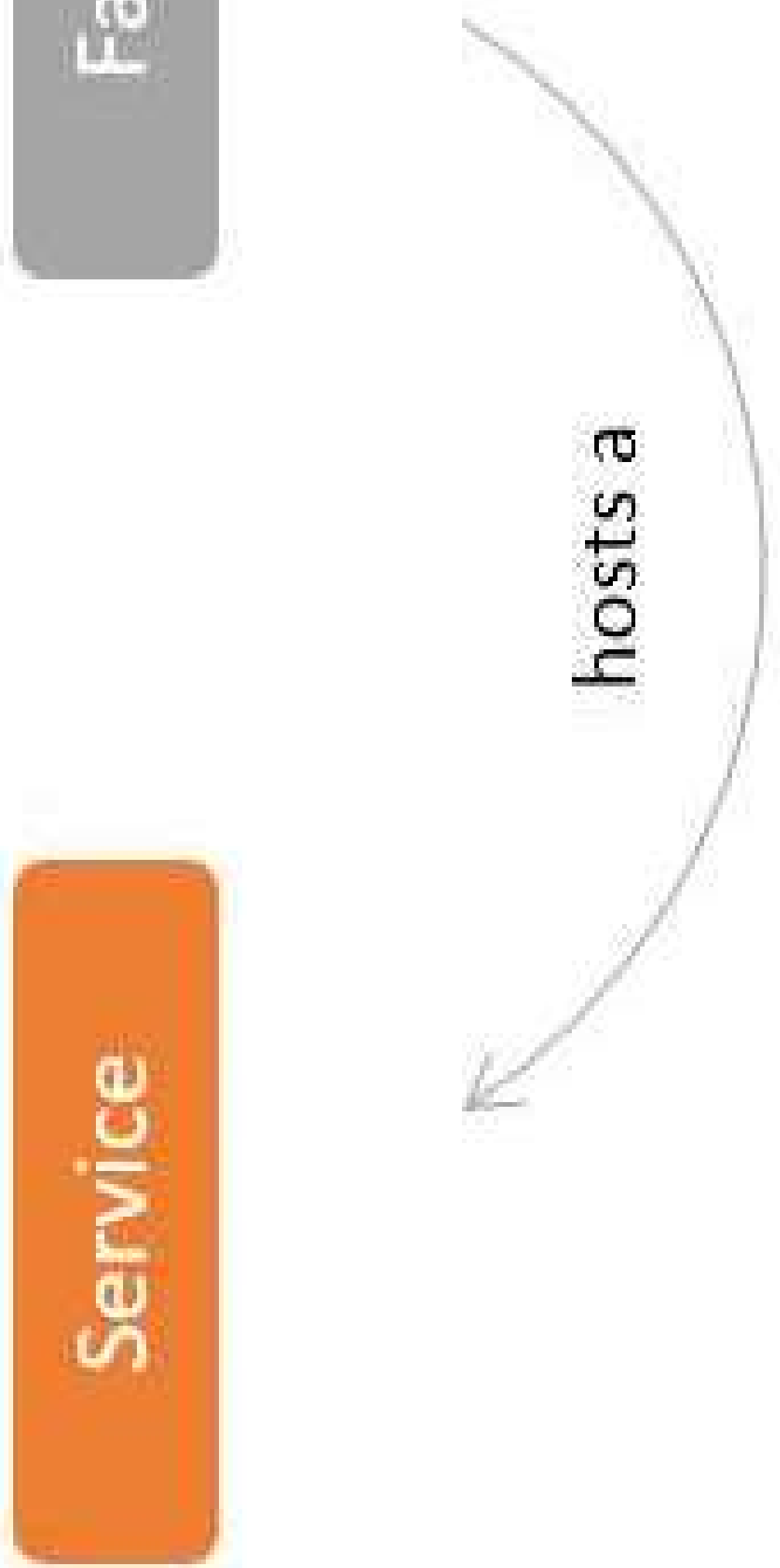
Fig 2

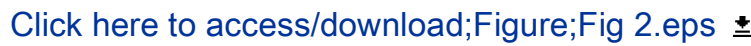

0
들
$\frac{10}{5}$
$\frac{2}{0}$
$\frac{10}{10}$

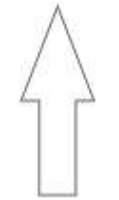

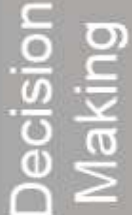

$=0$

$5 y$

$+\frac{2}{2}$

(1)

를

क

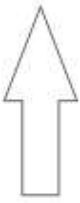

둥
$\frac{1}{0}$
0
0
8
8
0
0 


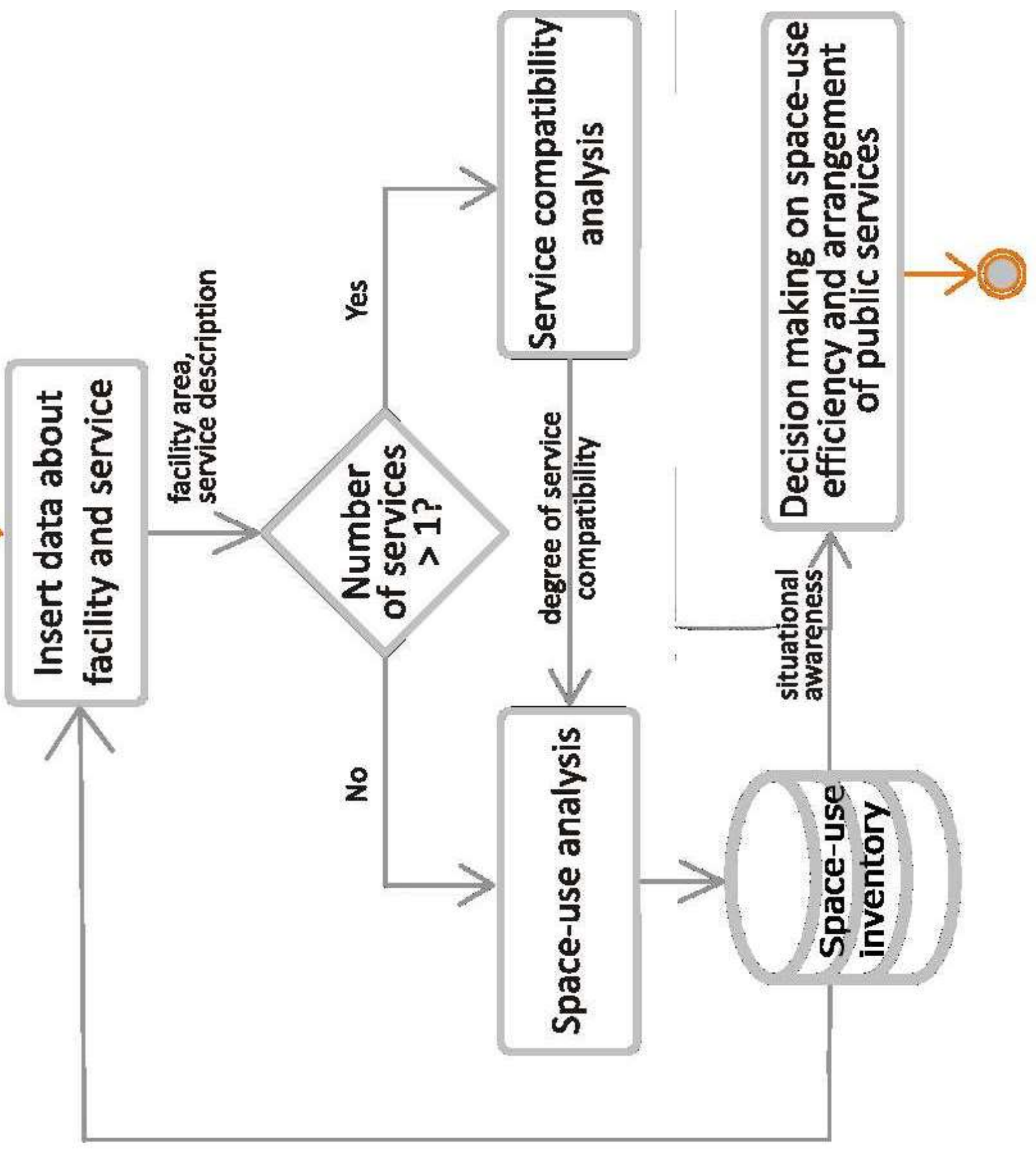




\section{facility area \\ Evaluation of space available in facility}

\section{number of users, type and duration of activities}

Evaluation of space necessary for service provision space demand

\section{Contrasting space demand} with space supply

Service demand for space in conformity with space supply

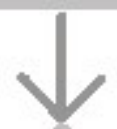

space

excess

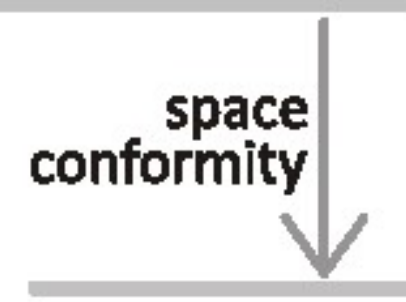

Space demand $=$ space supply? space scarcity or space excess?

space-use

Utilization rate calculous

utilization rate 


\section{Describe quantitatively service 1}

service description

\section{Describe quantitatively service 2}

service description

\section{Calculate the distance} between services

distance value

Present the degree of service compatibility

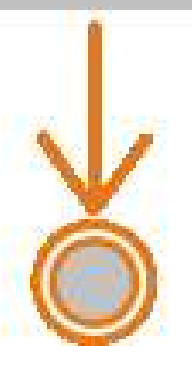


Fig 8

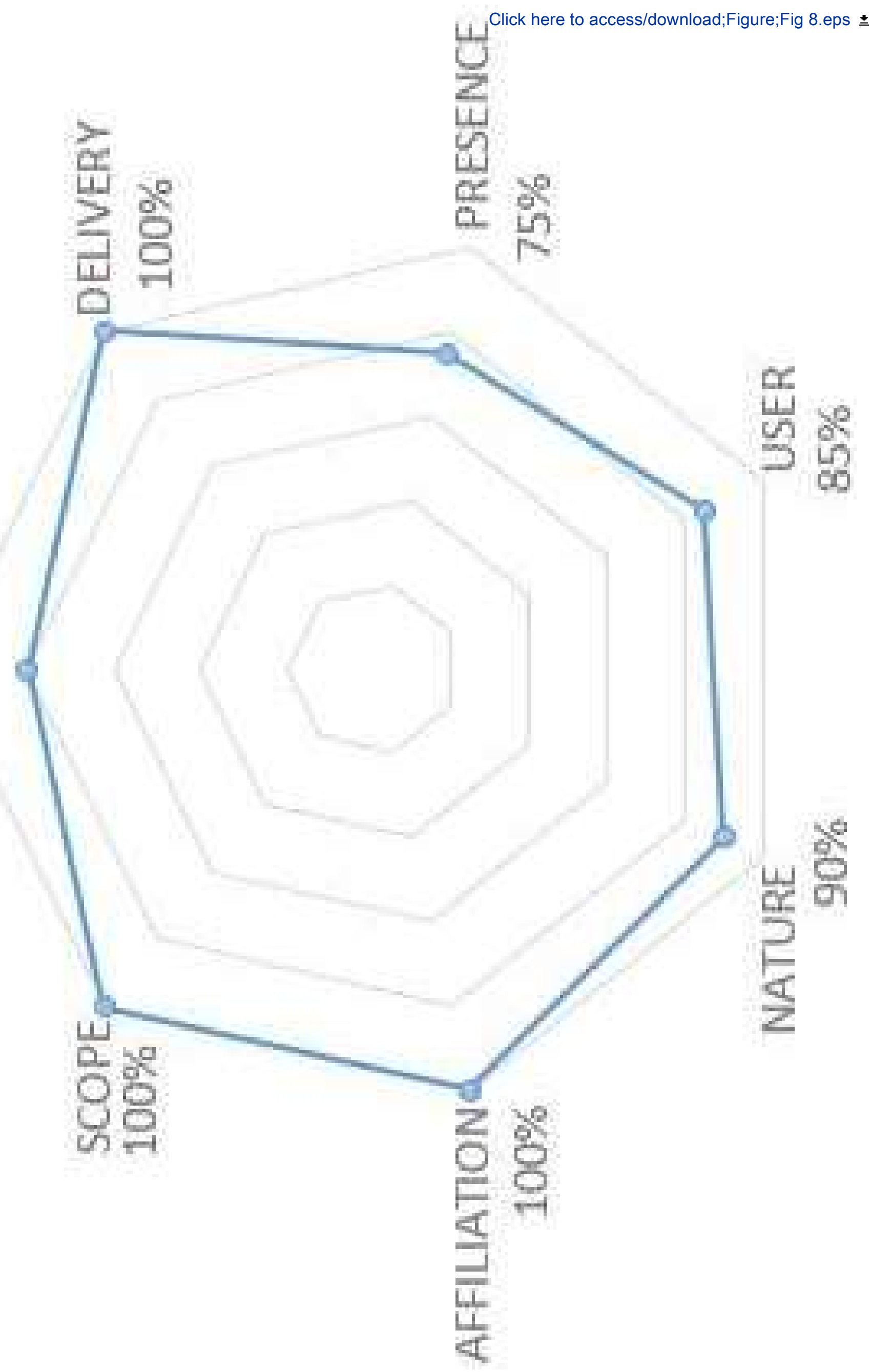


Fig 1. Relationship between service and facility.

Fig 2. Situation awareness in the context of decision making. (Adapted from Endsley \& Garland, 2000).

Fig 3. A high-level overview of the decision support framework for space-use efficiency and arrangement of public services.

Fig 4. Process of space-use analysis.

Fig 5. An overview of the process of service compatibility definition.

Fig 6. Compatibility matrix of 30 services. All values in \%. Source: Rusek et al., 2016.

Fig 7. Space-use inventory: spatial representation of public facilities with information about space utilization using Google Maps API.

Fig 8. Compatibility relationships between Service of City Historical Archive and Service of Image Research and Dissemination. 